\title{
PROGRESS IN THE KNOWLEDGE OF IRREGULAR SOLID ELECTRODE SURFACES*
}

\author{
A. J. Arvia and R. C. Salvarezza \\ Instituto de Investigaciones Fisicoquímicas Té́ricas y Aplicadas (INIFTA), Casilla de Correo 16, \\ Sucursal 4, (1900) La Plata, Argentina
}

(Received 13 September 1993; accepted 15 November 1993)

\begin{abstract}
Modern approaches to solid surface disorder provide a more rigourous way of defining roughness at solid surfaces, a crucial concept in electrocatalysis. The study of this type of surface comprises growth kinetics, geometric description, relaxation kinetics and influence of surface irregularities on different reactions.

Continuous rough columnar structured metal surfaces constitute a good model system for the investigation of a number of processes which are of special interest in heterogeneous catalysis, including electrocatalysis. The topography of these metal surfaces can be determined by scanning tunneling microscopy (STM) at different scales and can be described by means of the dynamic scaling theory applied to STM imaging.

Roughness relaxation kinetics followed by electrochemical techniques can be interpreted through a coalescence-type mechanism. Typical examples of adsorption and diffusion controlled electrochemical reactions on this type of electrodes are presented.
\end{abstract}

Key words: solid surface disorder, roughness, growth kinetics, dynamic scaling theory, nanoscopies.

\section{INTRODUCTION}

The advances made in recent years concerning the geometry of real systems and the observation of solid surfaces at the $\mathrm{nm}$ and atomic levels have provided new insights for attempting a more rigorous description of solid surfaces, particularly those surfaces which are of interest in heterogeneous catalysis and electrocatalysis[1-6].

The topography of any solid object can be considered as regular (ordered) or irregular (disordered)[7]. Regular and irregular surfaces can be continuous or discontinuous. Regular surfaces comprise smooth surface domains whereas irregular surfaces comprise weakly and strongly disordered surfaces[7].

Ordered surfaces can be adequately described by Euclidean geometry using the corresponding $D_{\text {rop }}$, the topological dimension of the object, and $d$, the Euclidean dimension of the space where the object is embedded. However, Euclidean geometry fails to describe disordered surfaces such as real solid surfaces. Fractal geometry which has been developed to address this problem[8], covers surface, mass, and pore fractality [7].

The fractal approach to disordered systems treats disorder as an intrinsic rather than a perturbative phenomenon $[7,8]$. In this approach $D$, the fractal dimension of the object, is comprised between $D_{\text {top }}$ and $d$, and the difference $D-D_{\text {top }}$ is taken as a measure of the system's disorder.

* This paper is based upon the lecture delivered by A. J. Arvia.
On the other hand, according to their behaviour under scale transformation[7] disordered systems exhibit either an isotropic disorder (self-similar fractals) or an anisotropic disorder (self-affine fractals)[7]. In contrast to the scale invariance of self-similar fractals at all scale lengths, self-affine fractals have different scale-invariance properties along different directions and can be characterized by a local surface fractal dimension $D_{\mathrm{z} 1}[8]$.

In this work, we explore the topographic characteristics of irregular metal electrodeposits prepared from either the electroreduction of hydrous metal oxides or from the electrodeposition of metal ions in the solution under adequate conditions. Attention will be focussed on a quantitative approach to the concept of roughness and on some electrochemical reactions at several well-defined large surface metal electrodes in relation to the theory of electrocatalysis. This type of electrode can be used as a model system for either continuous or discontinuous high surface area objects of interest in electrocatalysis. Accordingly, the results of surface characterization at the $\mathrm{nm}$ level, roughness decay kinetics, capacitance measurements, diffusion controlled reactions, and different adsorption processes on these type of electrode surfaces are considered.

\subsection{Ordered surfaces}

Ordered surfaces can be observed at terrace domains of single crystal surfaces. STM imaging at these domains reveals surface corrugations less than $0.1 \mathrm{~nm}$ introduced by the electronic charge density of atoms. Ordered regions at real single crystal surfaces are usually constrained to small areas because of 

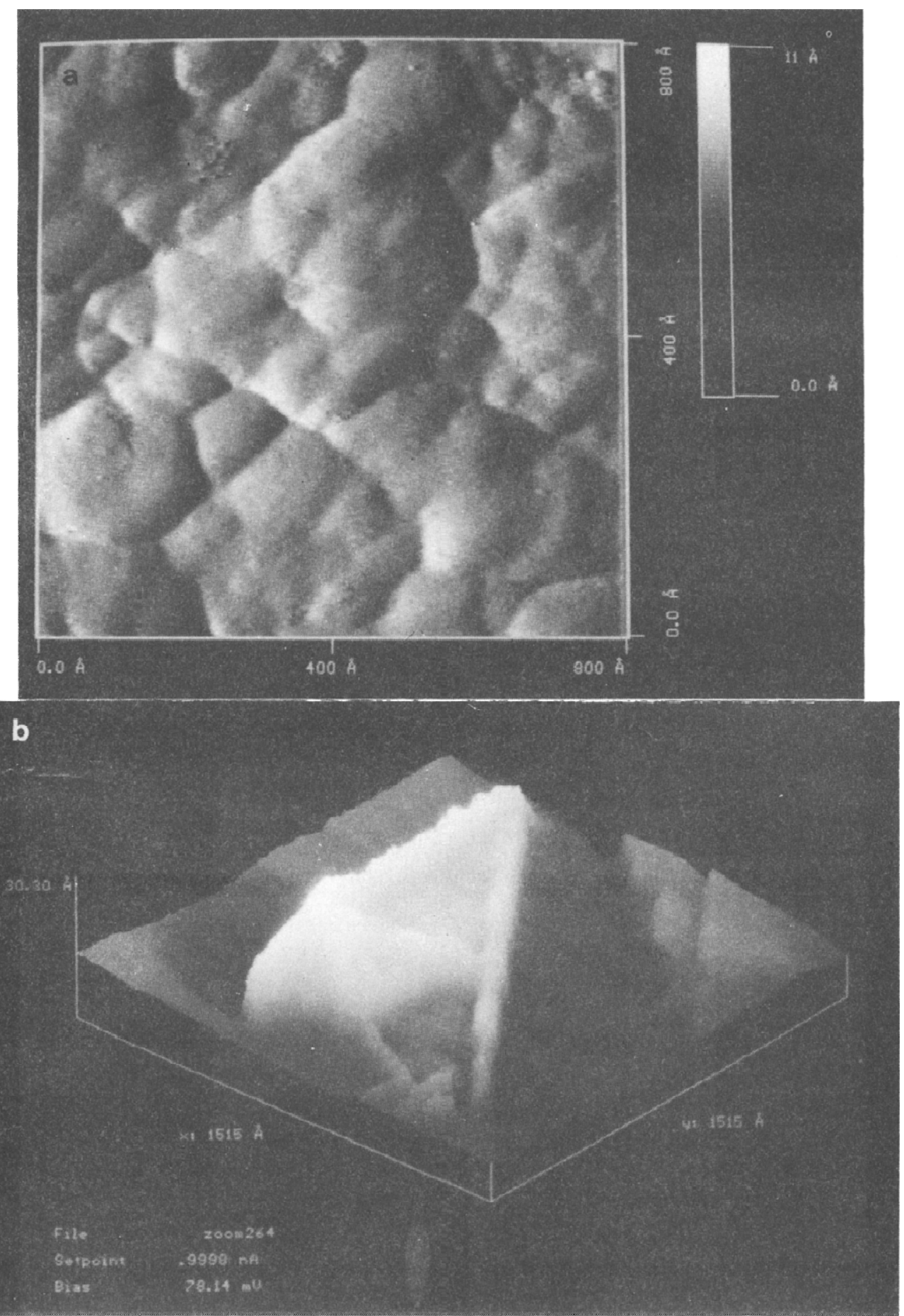

C

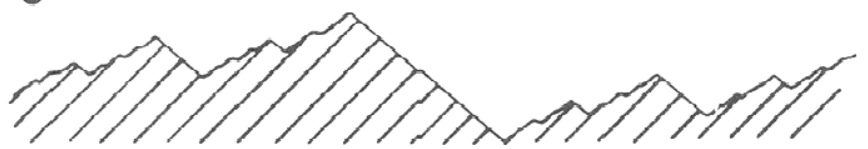

Fig. 1. (a) A $80 \times 80 \mathrm{~nm}^{2}$ STM image (top view) at a [111]-pole at a polyfaceted Au single crystal. (b) A $151.5 \times 151.5 \mathrm{~nm}^{2}$ STM image (3D-view) of a Ag crystallite electrodeposited on C(0001) substrate from acid aqueous solutions containing $\mathrm{Ag}^{+}$-ions. (c) Scheme of a weakly disordered contour according to a continuous model. 
a
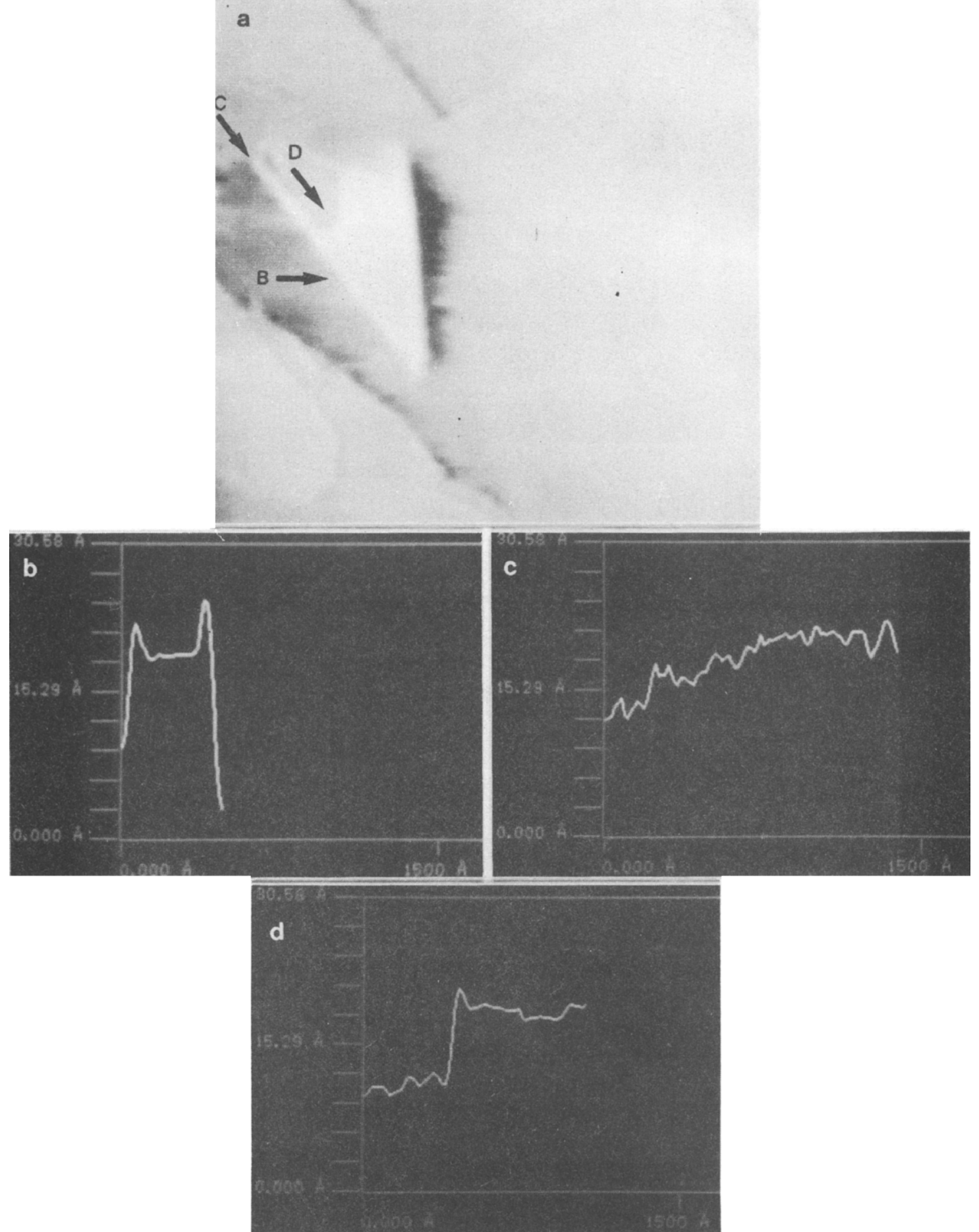

Fig. 2. (a) A $300 \times 300 \mathrm{~nm}^{2}$ STM image (top view) of a Ag crystallite deposited on a C(0001) substrate. (b), (c), (d) Contours of the crystallite taken in different directions as indicated by the arrows.

surface relaxation, surface reconstruction, structural and chemical defects[5].

\subsection{Weakly disordered metal surfaces}

Stepped crystal surfaces are typical examples of weakly disordered solid surfaces. STM images of the surface of a polyfaceted $\mathrm{Au}$ single crystal sphere at the [111]-pole (Fig. 1a) show small terraces and steps intersecting at $60^{\circ}$. In this case the surface disorder is introduced by the presence of structural defects. It should be noted that in real systems comprising particle dispersion as that found in metal electrocatalysts, at each particle there is always a contribution of terraces and stepped borders : of atomic size as seen, for instance, for a small $\mathbf{A g}$ crystal formed on C(0001) (Fig. 1b). The profile of these crystallites show clearly distinct directional 

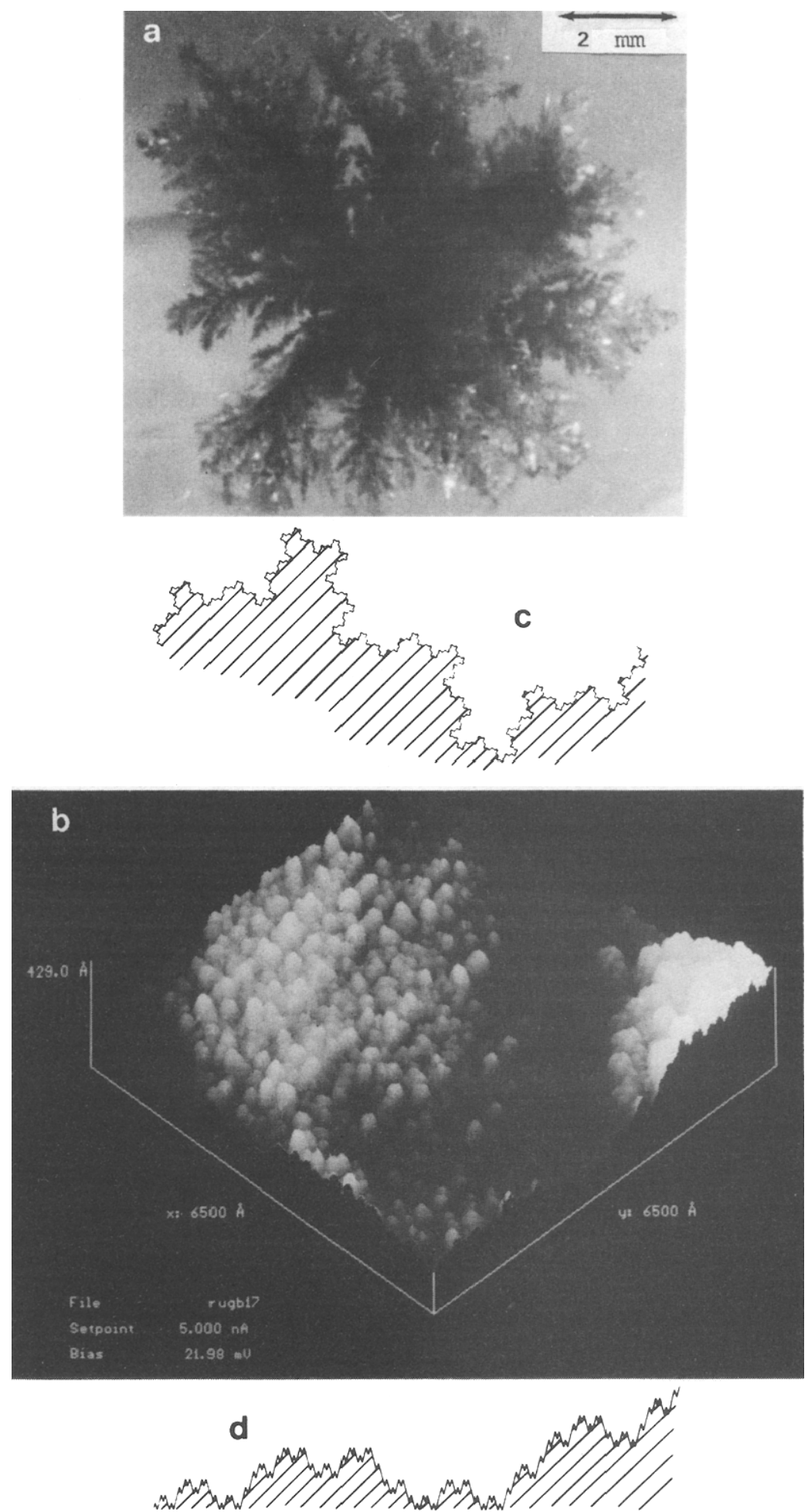

Fig. 3. (a) Cross-section of a dendritic Ag electrodeposit grown at a fast rate $\left(3000 \mathrm{~nm} \mathrm{~s}^{-1}\right)$ in a $3 \mathrm{D}$ electrochemical cell from $5 \times 10^{-3} \mathrm{M} \mathrm{Ag}_{2} \mathrm{SO}_{4}+10^{-2} \mathrm{M} \mathrm{H}_{2} \mathrm{SO}_{4}+0.5 \mathrm{M} \mathrm{Na}_{2} \mathrm{SO}_{4}$ gellified aqueous solution at $25^{\circ} \mathrm{C}$. (b) A $650 \times 650 \mathrm{~nm}^{2}$ STM image (3D-view) of a columnar Au electrodeposit grown from the electroreduction of a hydrous Au oxide layer at $100 \mathrm{~nm} \mathrm{~s}^{-1}$. (c), (d) Schemes of self-similar and self-affine contours according to a continuum model.

topographies (Fig. 2a-d)[9]. Despite the fact that for a stepped surface the surface fractal dimension, $D_{\mathrm{s}}=$ $D_{\text {lop }}$, the degree of disorder depends on the size of the yardstick used to probe the surface. It has been proposed that the set of points which are defined by step edges in the 2D-space behaves as a fractal[ 7 , 10]. For stepped surfaces the term marginal fractal surfaces has been proposed[11]. The 2D-contour of 
these surfaces according to a continuum model is shown in Fig. 1c.

\subsection{Strongly disordered metal surfaces}

Typical examples of mass and surface fractals with self-similar characteristics are dendritic metal deposits (Fig. 3a). On the other hand, typical examples of self-affine fractal surfaces are a variety of rough surfaces produced by different physical and chemical processes[12]. As an example the STM image of $\mathrm{Au}$ columnar structures is shown in Fig. 3b. The term rough surface has been suggested for a irregular surface without overhanging regions[13]. The absence of overhangings determines the self-affine character of rough surfaces, ie their anisotropic surface disorder. The 2D-contours of self-similar (Fig. 3c), and self-affine (Fig. 3d) fractal surfaces show the isotropic and the anisotropic characteristics of dendritic and columnar surfaces, respectively [7].

\section{FRACTAL CHARACTERIZATION}

The topography of rough physical surfaces is often stochastic but exhibits self-resemblance (Fig. 4) over a range of scales. Appropriate models for rough surfaces are continuous, single-valued self-affine fractal functions. A common way to deal with this type of surface is by means of the dynamic scaling theory[12].

\subsection{The dynamic scaling of rough surfaces}

The dynamic scaling theory consideres the development of a contour on a flat surface of length $L$ with $N_{\mathrm{s}}$ sites $\left(L \propto N_{\mathrm{s}}\right)$ at time $t=0$ (Fig. 5a)[12]. It is assumed that the rough surface growth proceeds in a single direction normal to $L$, ie increasing in height $(h)$ without overhangings. Then, the instantaneous surface height can be described by a singlevalued function of $x$ and $t$.

The instantaneous surface width, $\xi(L, t)$, which is taken as a measure of surface roughness, is defined by the root mean square of height fluctuations [14]:

$$
\xi(L, t)=\left[1 / N_{s} \sum\left[h\left(x_{i}\right)-\bar{h}\right]^{2}\right]^{1 / 2},
$$

where $\bar{h}$ is the average height normal to the surface direction. The dependence of $\xi(L, t)$ on $t$ and $L$ is given by $[12,14]$ :

$$
\xi(L, h) \propto L^{\alpha} f(x)
$$

where $f(x)=\bar{h} / L^{y}$. The function $f(x)$ has the following properties: $f(x)=$ const for $x \Rightarrow \infty$ and $f(x)=x^{\alpha / \gamma}$ for $x \Rightarrow 0$. Initially, $\xi$ increases with time as random fluctuations do according to:

$$
\xi(L, t \Rightarrow 0) \propto t^{\beta},
$$

where exponent $\beta$ describes roughness kinetics along growth directions. After a certain time (or thickness) a steady-state surface contour is reached. Then,

$$
\xi(L, t \Rightarrow \infty) \propto L^{\alpha},
$$

ie the surface under steady-state conditions becomes a scale-invariant self-affine fractal[12]. Globally con-
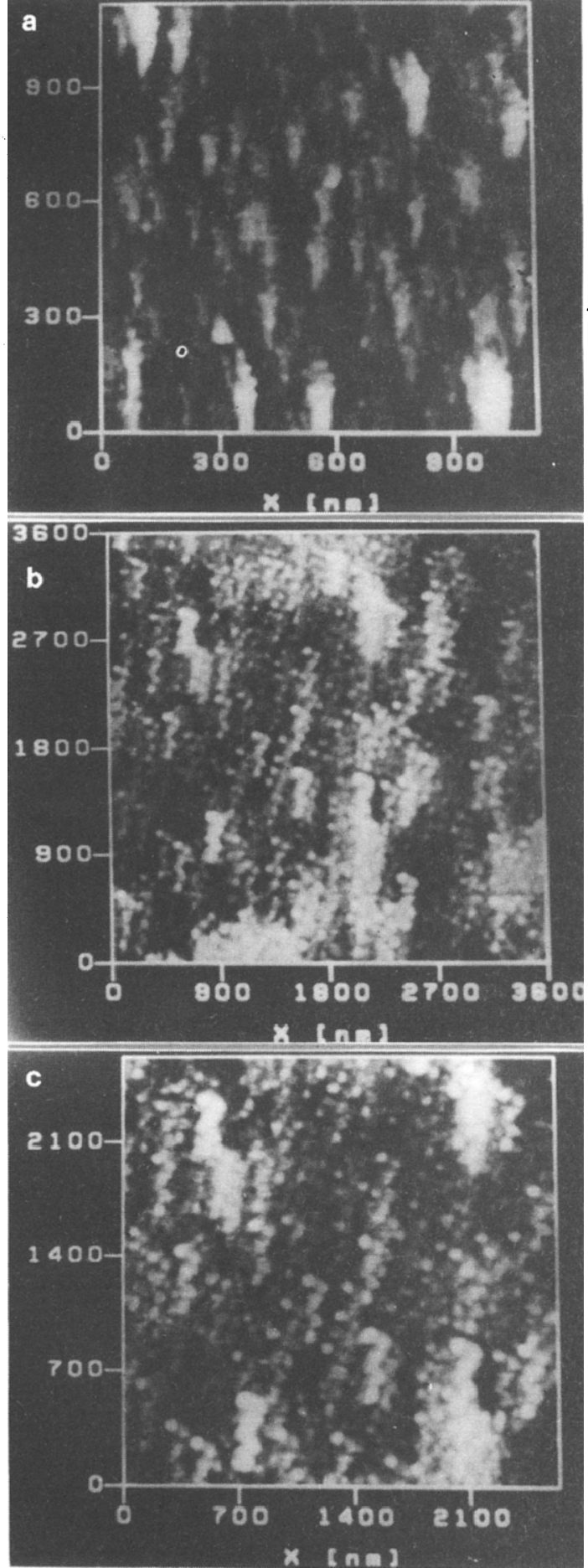

Fig. 4. STM images (top view) of vapor deposited Au film film at different magnifications. Note that void patterns exhibit a magnification-independent self-resemblance.

sidered, when the self-affine surface is probed with a yardstick larger than the interface width, it seems to be flat [8]: However, at scale lengths shorter than the interface width, the surface behaves as a rough surface and its roughness is characterized by the exponent $\alpha[8,12]$. This exponent is related to the local fractal $D_{\mathrm{s} 1}$ of the self affine surface by the 


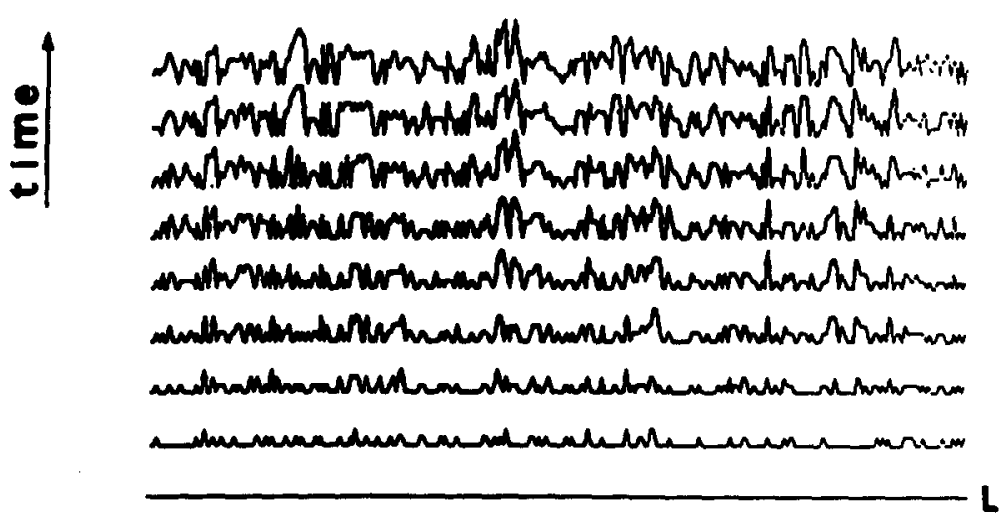

b

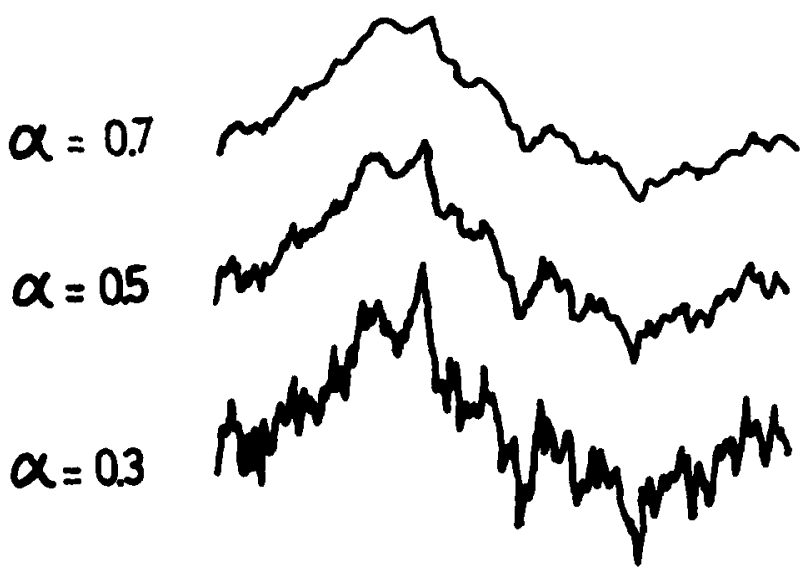

Fig. 5. (a) Evolution of a 1D-surface profile according to the ballistic growth model (from[12]). (b) Selfaffine profiles with different $\alpha$ values. As $\alpha$ decreases an increasing degrec of irregularity can be observed.

equation[12]:

$$
D_{\mathrm{sl}}=d-\alpha .
$$

The value of $D_{s 1}$ characterizes the self-affine surface in the "steep" regime, whereas $D_{\mathrm{sl}}=D_{\text {top }}$ does it in the global regime. This regime is reached when the horizontal extent is much greater than the vertical one on all scales $[8,12]$.

Values of $\alpha$ are associated with either jagged surfaces (anticorrelation) or well correlated smoothtextured surfaces, depending on whether they have small or large values, respectively (Fig. 5b).

Fractal surface characterization of rough surfaces has also been attempted through the analysis of data derived from optical microscopy, scanning electron microscopy (SEM) and TEM. Nevertheless, all these imaging techniques only provide a projection of the surface topography. Hence, as the vertical dimension becomes unaccessible, the application of the dynamic scaling theory is precluded. In contrast, STM and AFM (nanoscopies) have the advantage of producing experimental data in the vertical dimension yielding directly a 3D-pattern of the surface at the $\mathrm{nm}$ level. From the electrochemical standpoint, roughness characterization can also be made by in situ STM and in situ AFM imaging. Therefore, STM and AFM appear as very attractive techniques to characterize rough fractal surfaces because of their high lateral resolution and images in real space.

\subsection{STM characterization of fractal metal electrodeposits}

STM images of several metal deposits, such as Au vapour deposited films on glass, electrodeposited $\mathrm{Au}$ layers on polycrystalline $\mathrm{Au}$, and poly(o-toluidine) coatings on polyfaceted gold single crystals (Fig. 6), all of them produced at high rates, are generally regarded as rough structures made up of rounded elements with branched voids. Despite the differences in the substrate nature and growth mechanisms of those deposits, their topographies look very similar. It appears that common topographic patterns are spontaneously acquired, irrespective of the system. In fact, both theoretical considerations and 

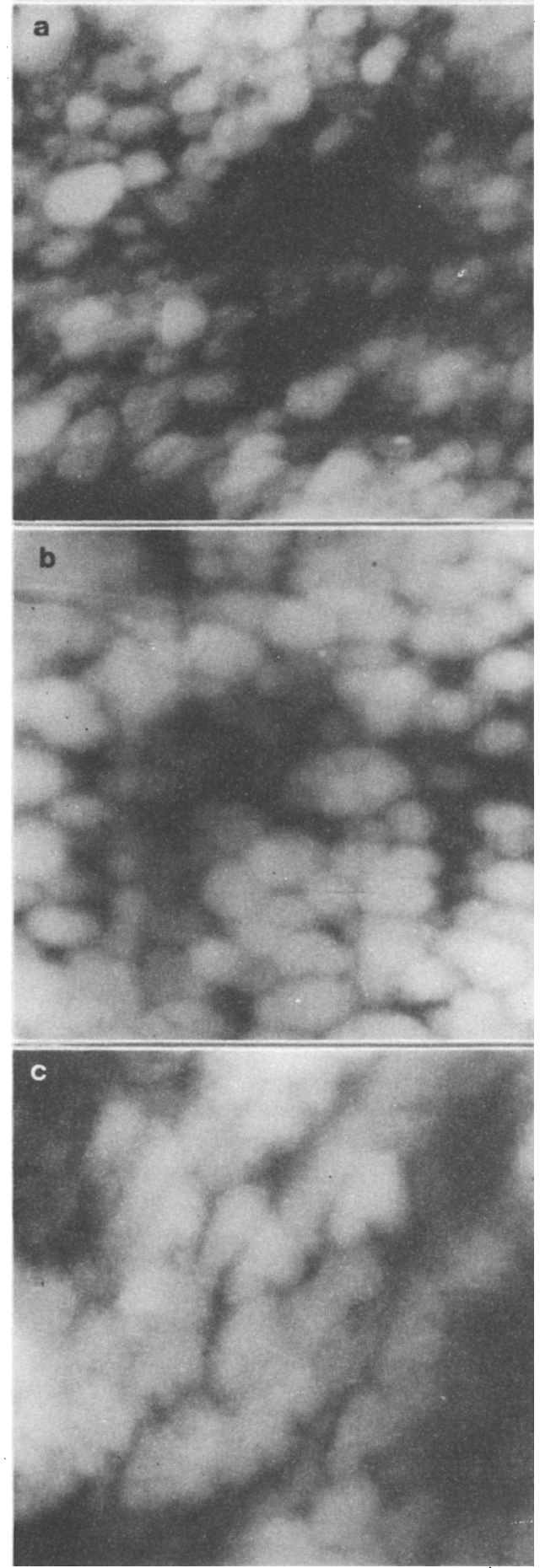

Fig. 6. STM images (top view) of different deposits grown at intermediate growth rates: (a) $600 \times 600 \mathrm{~nm}^{2}$, vapour deposited Au on glass; (b) $500 \times 500 \mathrm{~nm}^{2}$, electrodeposited $\mathrm{Au}$ on polycrystalline $\mathrm{Au}$; (c) $200 \times 200 \mathrm{~nm}^{2}$ electrodeposited poly(o-toluidine) on a polyfaceted $A u$ single crystal.

experimental results indicate that high rate grown surfaces reach a steady-state pattern characterized by universal self-affine fractal properties[12].

The dynamic scaling theory can be straightforwardly applied to STM data by setting $\xi^{i}=\xi_{\text {STM }}^{i}$,

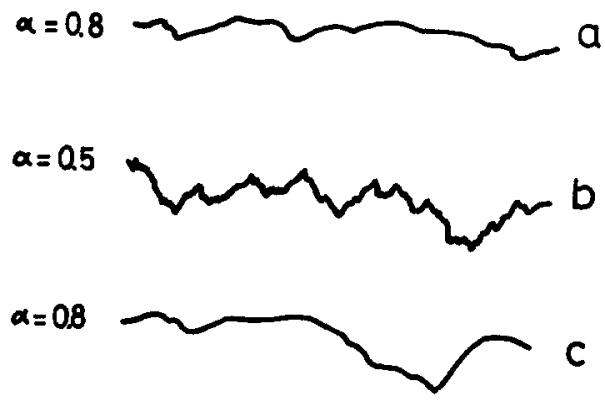

Fig. 7. STM profiles of Au electrodeposits: (a) slow growth rate $\left(0.01 \mathrm{~nm} \mathrm{~s}^{-1}\right)$; (b) fast growth rate $\left(100 \mathrm{~nm} \mathrm{~s}^{-1}\right)$; (c) fast growth ratc $\left(100 \mathrm{~nm} \mathrm{~s}^{-1}\right)$ after $7 \times 10^{4} \mathrm{~s}$ aging in $0.5 \mathrm{M} \mathrm{H}_{2} \mathrm{SO}_{4}$ at $50^{\circ} \mathrm{C}$. Values of $\alpha$ for each profile are also given.

where $\xi_{\text {STM }}^{i}$ is the root mean square roughness determined by STM scans in the $i$-direction $(i=x, y)$. More explicitly, the following proportionality can be used[15]:

$$
\xi_{\mathrm{STM}}^{i}\left(L_{\mathrm{s}}\right) \propto\left[\Sigma\left(h-h_{\mathrm{s}}\right)^{2}\right]^{1 / 2},
$$

where $h_{\mathrm{s}}$ is the average height of the deposit determined by STM scans in the $i$-direction, and $L_{\mathrm{s}}$ is a preset length measured along $S$, the STM scan length. Thus, considering that for self-affine fractals $t \propto M \propto \delta$, where $M$ and $\delta$ are the mass and the average thickness of the deposit, by changing $\delta$ the value of exponent $\beta$ can be obtained from the proportionality:

$$
\xi_{\mathrm{STM}}^{i}\left(L_{\mathrm{s}}\right) \propto \delta^{\beta}
$$

Besides, by determining the rms of $h$-fluctuations over each STM scan segment of length $L_{\mathrm{s}}$ in the $i$ direction, the exponent $\alpha$ can be evaluated from the proportionality:

$$
\xi_{\text {STM }}^{i} \propto L_{\mathrm{s}}^{\alpha} .
$$

At present, different methods have been developed to obtain $\alpha$ from the analysis of STM images. Thus, the single image dynamic-scaling, the multiple image dynamic-scaling method, the perimeter-area and the Fourier transform methods can be used to obtain $\alpha$ and then, from equation (8), the $D_{\mathrm{s1}}$ value[16].

The application of these methods to STM images of $\mathrm{Au}$ electrodeposits grown from the high rate electroreduction of hydrous $\mathrm{Au}$ oxides previously formed on polycrystalline Au (Fig. 3b), yields two values of $\alpha$, namely $\alpha(\mathrm{I})$ and $\alpha(\mathrm{II})$, depending on whether $L_{\mathrm{s}}$ is either smaller or greater than $d_{3}$, the average diameter of the columnar tips (Fig. 6) [16]. Average values of $\alpha(I), \alpha(I I)$, and $L_{\mathrm{s}}$ for different numbers of averaged STM images [N(I) and N(II)] for each sample, are summarized in Table 1[16]. The average values are $\langle\alpha(\mathrm{I})\rangle=0.90 \pm 0.07(\mathrm{~N}(\mathrm{I})=153)$ and $\langle\alpha(\mathrm{II})\rangle=0.49 \pm 0.07(\mathrm{~N}(\mathrm{II})=128)[16]$. Within the experimental errors, values of $\alpha$ are independent of $\delta$, the average film thickness, as it should be expected when equation (8) is fulfilled. These results have also been proved to be free of STM tip effects. The fact that $\langle\propto(I)\rangle \cong 1$ for $L_{s}<d_{s}$, suggests that smoothening of the columnar structure is caused by surface diffusion of $\mathrm{Au}$ atoms. The influence of 
Table 1. Values of $\alpha(\mathrm{I}), \alpha(\mathrm{II})$ and $L_{\mathrm{a}}$ resulting from Au electrodeposits[16]

\begin{tabular}{rcrcrc}
\hline $\begin{array}{c}c \\
(\mathrm{~nm})\end{array}$ & $\alpha(\mathrm{I})$ & $N(\mathrm{I})$ & $\alpha(\mathrm{II})$ & $N(\mathrm{II})$ & $\begin{array}{c}L_{1} \\
(\mathrm{~nm})\end{array}$ \\
\hline & $0.96 \pm 0.07$ & 33 & $0.43 \pm 0.09$ & 17 & 24 \\
160 & $0.89 \pm 0.09$ & 23 & $0.41 \pm 0.05$ & 9 & 25 \\
500 & $0.91 \pm 0.06$ & 29 & $0.50 \pm 0.06$ & 32 & 30 \\
560 & $0.89 \pm 0.04$ & 17 & $0.50 \pm 0.06$ & 18 & 32 \\
2800 & $0.93 \pm 0.07$ & 23 & $0.52 \pm 0.07$ & 16 & 49 \\
9100 & $0.90 \pm 0.06$ & 28 & $0.51 \pm 0.08$ & 24 & 50 \\
11500 & $0.86 \pm 0.06$ & 21 & $0.45 \pm 0.06$ & 12 & 79 \\
& $\langle\alpha(\mathrm{I})\rangle=0.90 \pm 0.07$ & 153 & $\langle\alpha(11)\rangle=0.49 \pm 0.07$ & 128 & \\
\hline
\end{tabular}

surface diffusion on the topography of the columnar structured metal electrodeposits has also been inferred by aging rough $\mathrm{Au}$ and $\mathrm{Pt}$ columnar structures with $\alpha \cong 0.5$ in $0.5 \mathrm{M} \mathrm{H}_{2} \mathrm{SO}_{4}$ for $7 \times 10^{4} \mathrm{~s}$ at $T=323 \mathrm{~K}$ (Fig. 7)[17]. For Au electrodeposits aging results in the decrease from $\alpha \cong 0.5$ to $\alpha \cong 0.75[17]$. After correction[18] this figure yields $\alpha \cong 1$. On the other hand, for aged Pt deposits $\alpha \cong 0.5$ remains unchanged. These results confirm that for a $T<0.5$ $T_{\mathrm{m}}$ temperature condition, where $T_{\mathrm{m}}$ is the absolute melting temperature of the metal, surface diffusion eliminates $\mathrm{Au}$ surface irregularities. Otherwise, surface mobility at rough Pt deposits ends up to be very slow to produce a similar effect. This interpretation is further supported by the fact that the activation energies for surface diffusion of $\mathrm{Au}$ and $\mathrm{Pt}$ atoms on columnar $\mathrm{Au}$ and $\mathrm{Pt}$ electrodes in $0.5 \mathrm{M} \mathrm{H}_{2} \mathrm{SO}_{4}$ are 14 and $20 \mathrm{Kcal} \mathrm{mol}^{-1}$, respectively[17].

\section{ELECTROCHEMICAL BEHAVIOUR OF STRONGIYY DISORDERED METAL SURFACES}

\subsection{Roughness decay at metal electrodes}

Roughness decay at columnar structured metal electrodes occurs spontaneously under either open circuit or applied potential conditions $[19,20]$. The kinetics of this process depends on the electrolyte composition and temperature. The knowledge of the roughness decay rate becomes of importance for establishing the life-time of this type of electrode in particular environmental and operating conditions.

As discussed in the preceding section the surface of columnar structure rough deposites probed at length scales smaller than the columnar size behaves as a smooth surface. This behaviour can be understood through a detailed analysis of STM images of these surfaces (Fig. 3b). Accordingly, the topography of these electrodes at the $\mathrm{nm}$ level can be described as an arrangement of material domains which constitutes the columns' tips together with void domains which correspond to intercolumnar spaces. These features represent a porous-like contribution to the overall roughness. Likewise, columnar tips themselves are made up of the agglomeration of a large number of cluster-like elements which determine a new kind of irregularity also contributing to the total roughness of the sample. Therefore, either one type of roughness contribution or the other may be dominant in a particular surface reaction, depending on the size of the interacting species. Correspondingly, those processes undergoing at those rather smooth domains of cluster-like elements, ie at object sizes smaller than the column diameter, can be handled with conventional kinetics. An example of this type of process is the above mentioned "smoothing effect" which operates on rough surfaces.

Roughness decay data can be reasonably interpreted by means of Chakraverty's model for particle growth[21]. This model considers a population of 3D-hemispherical nuclei placed on a flat 2Dsubstrate with a certain nuclei size distribution. In order to minimize the surface free energy, largest nuclei grow by incorporating adatoms into the nuclei/substrate interface from the preferential dissolution of the smallest nuclei. This kinetic description is, in principle, applicable to roughness relaxation at columnar structured $\mathrm{Au}$ and $\mathrm{Pt}$ electrodes on the basis of STM imaging data. In these cases, small rounded nuclei constitute the tips of large columns (Fig. 3b). These domains can be related to the flat substrate in Chakraverty's model where metal adatom transport from small dissolving tips to coalescing column domains takes place, the surface mass transport process undergoing exclusively among contacting small column domains. Thus, larger columns' tips tend to grow at the expense of smaller ones, whereas deep pores and crevices existing between large columns remain. This kinetic model can explain why the complete roughness decay of these metals can not be attained[19].

According to Chakraverty's model, when surface diffusion becomes the rate controlled step, $r$, the average radius of stable nuclei, increases with $t$, the relaxation time, as given by[21]:

$$
\left(r-r_{0}\right)^{4}=2 \gamma a^{4} D_{\text {is }} t / k T
$$

where $r_{0}$ is the initial average radius of those particles forming the rough electrodeposit, $\gamma$ is the average surface tension of the metal in the environment, $a$ is the lattice parameter of the metal deposit, and $D_{\text {is }}$ is the average surface diffusion coefficient of deposited metal atoms.

To study the roughness decay kinetics we use the simplest columnar model under the condition that $h \gg r$, where $h$ is the average columnar height $(h \cong \delta$ ) and $r$ is the average columnar radius $\left(r \cong d_{s} / 2\right)[19]$. For this model, $R$, the surface roughness factor, is related to $h$ and $r$ by the equation:

$$
R \simeq \pi h / 3 r .
$$

Equation (10) allowed us to determine the average value of $r$ from $R$, the roughness factor which can be voltammetrically evaluated from $O$-electrodesorption measurements for metals such as $\mathrm{Pt}$ and 
Au. Values of $r$ derived from equation (10) are in good agreement with those obtained from STM imaging. The value of $h$ can also be derived from the electrodeposit cross-section measured from SEM micrographs (Fig. 8). The spontaneous decrease in $R$ can be easily followed through conventional electrochemical techniques such as voltammetry $[19,20]$ and capacity measurements in concentrated solutions at low frequency[22]. Thus, for columnar $\mathrm{Au}$ and $\mathrm{Pt}$ electrodeposits in contact with aqueous acid solutions, roughness relaxation fits reasonable linear $R^{-4}$ vs. $t$ relationships under either potentiostatic or open circuit potential conditions in different electrolytes (Fig. 9) [19, 20].

Using the simple columnar model presented in section 5.1., and further assuming that the columnar height change is much smaller than that of the columnar radius, ie $\mathrm{d} h / \mathrm{d} t \ll \mathrm{d} r / \mathrm{d} t$, equations (9) and (10) lead to [19]:

$$
R=h /\left(2 \gamma a^{4} D_{\mathrm{is}} t / k T+r_{0}\right)^{1 / 4} .
$$

Then, by plotting equation (11) as $R^{-4}$ vs. $t$ (Fig. 9), the value of $D_{\text {is }}$ can be estimated for several metals immersed in aqueous electrolyte solutions provided that $\gamma$ is known. In principle, at a constant potential, the value of $\gamma$ depends on the solution composition, particularly on the presence of adsorbable species. However, it was demonstrated that $\Delta \gamma$, the change in $\gamma$ induced by strongly adsorbed anions[20] and molecules[23], produces a neglegible effect on the value of $D_{\text {is }}$ estimated from equation (11). Thus,

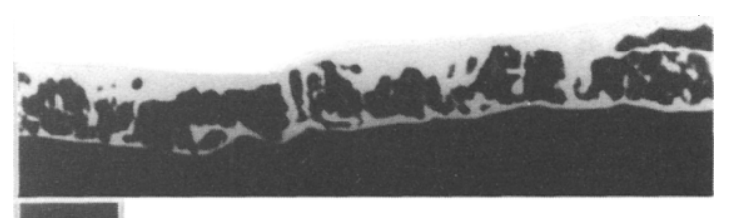

\section{$1 \mathrm{Nm}$}

Fig. 8. SEM micrograph (cross-section) of a columnar Au electrodeposit. Bar indicates $1 \mathrm{~m} \mu$ scale (reproduced from[19]).

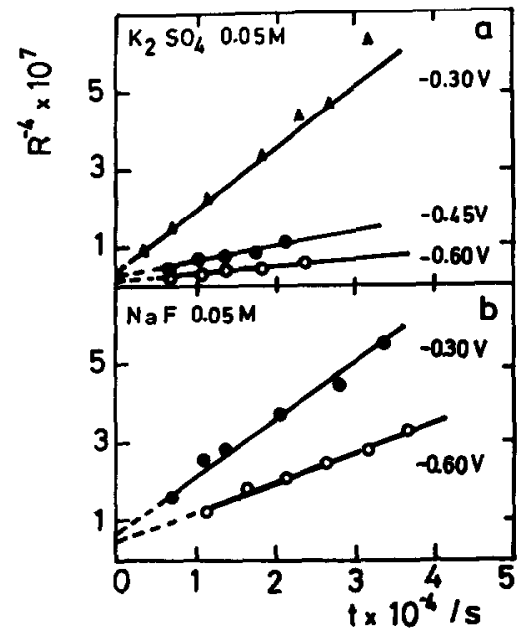

Fig. 9. $R^{-4}$ vs. $t$ plots for columnar Au electrodeposits. The electrodeposit aging was performed at constant potential and $298 \mathrm{~K}$ in (a) $0.05 \mathrm{M} \mathrm{H}_{2} \mathrm{SO}_{4}$ and (b) $0.05 \mathrm{M} \mathrm{NaF}$. under open circuit conditions, it resulted $D_{\mathrm{is}}=5$ $\times 10^{-14} \mathrm{~cm}^{2} \mathrm{~s}^{-1}$ for $\mathrm{Au}$, and $D_{\mathrm{is}}=10^{-18} \mathrm{~cm}^{2} \mathrm{~s}^{-1}$ for Pt both of them in $1 \mathrm{M} \mathrm{H}_{2} \mathrm{SO}_{4}$ at $298 \mathrm{~K}$ [19].

It has been found that for columnar polycrystalline $\mathrm{Au}$ and $\mathrm{Pt}$, in the $273-325 \mathrm{~K}$ range, the temperature dependence on $D_{\mathrm{is}}$ fulfils an Arrhenius plot yielding $Q^{*}=14 \pm 2 \mathrm{Kcal} \mathrm{mol}^{-1}$ for $\mathrm{Au}$, and $Q^{*}=19 \pm 2 \mathrm{Kcal} \mathrm{mol}^{-1}$ for $\mathrm{Pt}[19]$. These figures have been interpreted through the surface diffusion mechanism proposed for those processes taking place at metal/gas interfaces[24]. The comparison of these values of $Q^{*}$ to those derived from rough $\mathrm{Au}$ and $P t$ electrode surfaces suggests that the roughness decay kinetics of these metals in contact with conducting solutions fulfills a surface diffusion mechanism under a vacancy displacement control.

On the other hand, it has been empirically demonstrated that the value of $D_{\text {is }}$ also depends on the presence of adsorbates as these species modify the potential distribution at the electrical double layer $[20,23]$. For instance, pyridine, which is strongly adsorbed on $\mathrm{Au}$ in $1 \mathrm{M} \mathrm{H}_{2} \mathrm{SO}_{4}$, decreases the value of $D_{\text {is }}$ for this metal in about one order of magnitude[23], in contrast to the presence of $\mathrm{Cl}^{-}$. ions which, under comparable conditions, increase the value of $D_{\text {is }}$ presumably due to the formation of a chloro-complex adsorbate on $\mathrm{Au}$, acting as an intermediate species in the electrodissolution of this metal. In this case, it has also been found that the value of $D_{\text {is }}$ increases as the applied potential is positively shifted, ie in the direction of increasing the degree of $\mathrm{Au}$ surface coverage by $\mathrm{Cl}^{-}$-ions (Fig. 10) [20]. Conversely, for $\mathrm{Au}$ in contact with an acid solution containing either $\mathrm{F}^{-}$or $\mathrm{SO}_{4}^{-2}$ ions, $D_{\text {is }}$ values are smaller than those found in $\mathrm{Cl}^{-}$-ion containing solutions. Furthermore, a maximum value of $D_{i s}$ is attained just immediately after the $\mathrm{OH}$ adsorbates on Au are formed[20].

\subsection{Diffusion to fractal surfaces}

In the preceding section an example of a kinetic process on rough metal surfaces which can be handled through a Euclidean model was considered. Now another type of reaction for which the degree of surface irregularity plays an important role is discussed. Let us consider the case of a redox electrochemical reaction with both reactant and product in

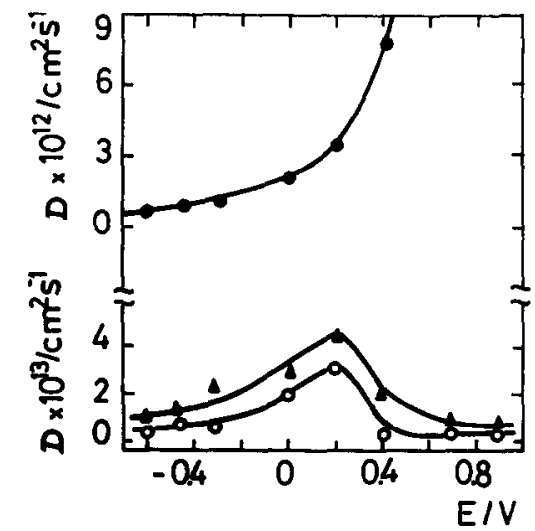

Fig. 10. $D$ vs. $E$ plots for columnar Au electrodeposits in aqueous solutions at $T=298 \mathrm{~K}$ : (O) $0.05 \mathrm{M} \mathrm{NaCl}$; (A) $0.05 \mathrm{M} \mathrm{H}_{2} \mathrm{SO}_{4} ;(\mathrm{O}) 0.05 \mathrm{M} \mathrm{NaF}$ (reproduced from[20]). 
the solution under diffusion control. For this type of reaction it was shown that the time-dependence of the diffusion flux on a self-affine or a self-similar fractal surface differs from that on a Euclidean surface[25]. The potentiostatic current (I) vs. time $(t)$ response of such a reaction under diffusion controlled regime is given by the general expression[25]:

$$
i \propto t^{-n},
$$

with

$$
n=\left(D_{\mathrm{s}}-1\right) / 2 \text {. }
$$

It should be noted that for a smooth surface $\left(D_{\mathrm{s}}=\right.$ 2), $n$ becomes 0.5 and the usual proportionality $i \propto t^{-0.5}$ is obtained. A similar behaviour is expected from a fractal electrode when the diffusion layer width is either much smaller than the size of the smallest irregularities of the electrode or thicker than the size of the largest irregularities. For the latter, the electrode behaves as a smooth electrode, ie the diffusion layer width acts as a time-dependent yardstick. Therefore, there is a lapse in which the fractality of the electrode surface is revealed through equation (13). Starting from $t=0$, the first crossover cannot be easily detected, but $t_{c}$, the crossover time for the fractal to non-fractal transition, is given by[25]:

$$
\lambda^{2} \cong D_{i} t_{c}
$$

where $\lambda$ is the size of the largest irregularities and $D_{i}$ is the diffusion coeflicient of the $i$-reactant in the solution. In the fractal regime the diffusion kinetics changes due to the fractal character of the electrode surface leading to $n>0.5$ in equation (12).

Equation (12) has been tested by plotting $\log I$ vs. $\log t$ for the reaction:

$$
\left[\mathrm{Fe}(\mathrm{CN})_{6}^{-4}\right]=\left[\mathrm{Fe}(\mathrm{CN})_{6}^{-3}\right]+\mathrm{e}^{-} \text {, }
$$

under diffusion control on a stepped Au single crystal $\left(D_{\mathrm{s}}=2.0\right)$ and on columnar structured $\mathrm{Au}$ electrodes $\left(D_{\mathrm{s}}=2.5\right)$ (Fig. 11)[26]. For these electrodes it results $n=0.76 \pm 0.05$ for $t<1 \mathrm{~s}$, whereas for the stepped Au single crystal electrode, it yields $n=0.50 \pm 0.05$. Experimental values of $n$ are compared to those values of $n$ predicted from equation (12) taking the corresponding $D_{\mathrm{s}}$ values in Table $2[26]$.

\subsection{Impedance of fractal capacitive electrodes}

Rough metal electrodes can display an anomalous frequency dependence on the electrical impedance, a fact which has been the subject of considerable interest $[27,28]$. The constant-phase-angle (CPA) frequency $(\omega)$ vs. impedance $(Z)$ relationship of the form:

$$
Z=R_{0}+k(j \omega)^{-n},
$$

has been presented in a number of publications on the basis of data obtained from rough electrodes in the absence of faradaic processes (blocking

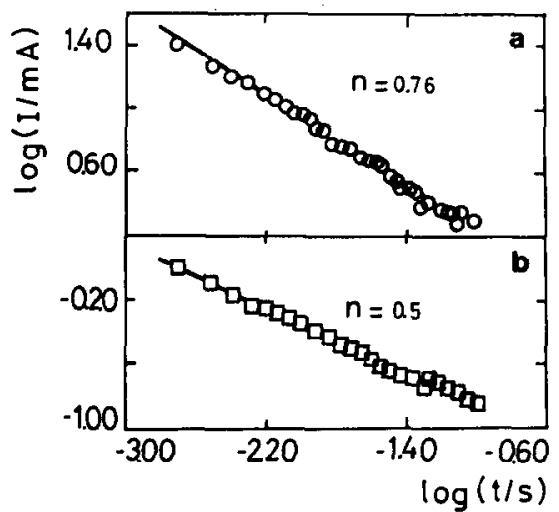

Fig. 11. $\log I$ vs. $\log t$ plot for the $\left[\mathrm{Fe}(\mathrm{CN})_{0}^{-4}\right] \Rightarrow$ $\left[\mathrm{Fe}(\mathrm{CN})_{6}^{-3}\right]$ electro-oxidation reaction under diffusion control: (a) Fractal electrodeposited Au electrode $\left(D_{8}=\right.$ 2.5); (b) polyfaceted Au electrode $\left(D_{s}=2.0\right)$ (from [26]).

electrodes). In equation (16) $R_{0}$ represents the electrolyte resistance, $\omega$ is the frequency of the $a c$ applied potential, $n$ is the CPA exponent, $k$ is a constant, and $j=\sqrt{ }-1$. The value of $n$ ranges from 1 , for an ideally smooth surface, to 0.5 as in the case of a surface consisting of cylindrical pores[28]. The validity of equation (16) has been proved for different electrode surfaces as in the case of electrodeposited Au electrodes in diluted acid solutions and with high $\omega$ values, covering the double layer potential range (Fig. 12)[29]. It should be noted that for $R=1$ (smooth electrode surface), $n=0.95$, whereas for $R>10, n \cong 0.72$.

Self-similar and self-affine fractal surfaces have been theoretically and experimentally explored with the purpose of explaining the "anomalous" values of CPA and establishing a relationship between $n$ and $D_{\mathrm{s}}[30,31]$. Different models assuming that the electrolyte conductivity is finite and the capacitance density is uniform along the surface lead to equation (16), although the relationship between $n$ and $D_{s}$ depends on the model. Le Mehauté[30] and Nyikos and Pajkossy[31] relate $n$ and $D_{\mathrm{s}}$ for a 3D-surface through equation:

$$
n=\left(1 / D_{\mathrm{s}}\right)+1 \text {. }
$$

This type of relationship has also been found by computer simulations by Meakin and Sapoval[32] for a variety of ramified fractals, and experimentally confirmed for $\mathrm{Ag}$ dendritic deposits with $D_{\mathrm{g}}=$ 2.5[3:]. On the other hand, Liu has proposed[34]:

$$
n=3-D_{s} \text {, }
$$

and other relationships have also been reported for model electrodes $(159,160)$. For self-affine fractal surfaces as electrodeposited $\mathrm{Au}$ with $R>10$ and $D_{\mathrm{s}} \cong 2.5$ none of these relationships exactly holds[29].

Table 2. Expected and measured $n$ values for Au electrodes $[17,26]$

\begin{tabular}{lccc}
\hline \multicolumn{1}{c}{ Electrode } & $D_{s}$ & $n$ (expected) & $n$ (measured) \\
\hline Polyfaceted Au single crystal & 2.00 & 0.50 & 0.49 \\
Fast grown electrodeposits & 2.45 & 0.73 & 0.76 \\
"Aged" fast grown electrodeposits & 2.15 & 0.58 & 0.62 \\
\hline
\end{tabular}




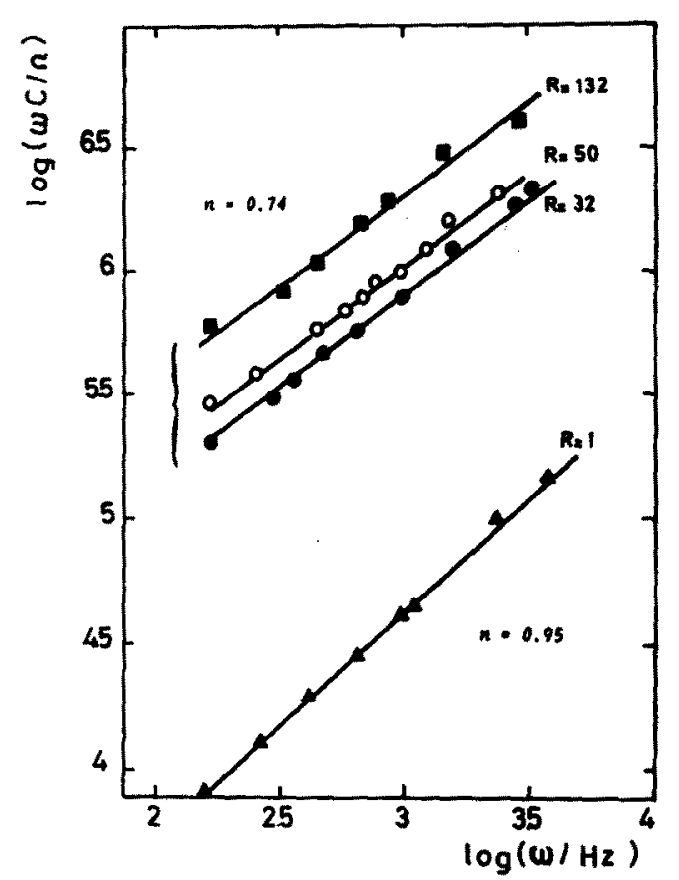

Fig. 12. Log $\omega C$ vs. $\log \omega$ plots for electrodeposited Au films with different $R$ values in $10^{-3} \mathrm{M} \mathrm{H}_{2} \mathrm{SO}_{4}$ at $298 \mathrm{~K}$ (from [29]).

A perturbative approach to the frequency dispersion problem indicates that only suitable rough surfaces display anomalous impedance. This problem strongly constrains any relation between $D_{3}$ and $n$. Thus, with exception of model electrodes of DLA surfaces no general conclusion can be drawn[35].

\subsection{Molecular adsorption on stabilized columnar gold} electrodes

At constant concentration and temperature, the equilibrium surface coverage degree on a stable solid substrate is determined by the substrate-adsorbate and adsorbate-adsorbate specific interactions, the applied potential and topographic features, which include irregularity size and their distribution at the substrate, and adsorbate size and shape.

The influence of topographic features on molecular adsorption can be determined by adequately selecting solid substrate topographies with the same crystallographic characteristics, and adsorbates of different sizes, excluding any interference of faradaic reactions. Then, for certain adsorbate/substrate irregularity size $(A / S)$ ratios the influence of unaccessible substrate areas (excluded volume), and eventually fractal surface characteristics should be noticed. This adsorption approach is equivalent to scaling the substrate surface with a yardstick consisting of the proper adsorbate species, either an atom, a molecule, or a radical species. Accordingly, for a particular rough surface, three limiting possibilities can be found (Fig. 13), namely, when $A / S \Rightarrow 0$, the entire substrate surface becomes accessible to the adsorbate (case 1); when $0<A / S<\infty$, the existence of excluded volume and surface fractality manifest (case 2); when $A / S=\infty$, then roughness contribution tends to disappear as only neighbour tips of the rough topography are accessible to adsorption, ie
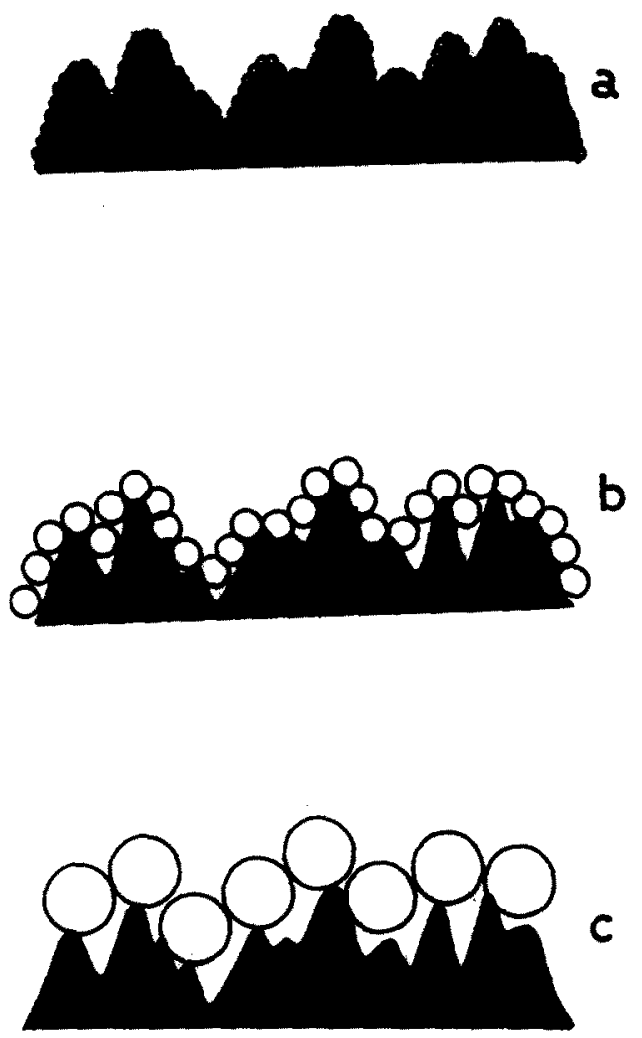

Fig. 13. Schemes of monolayers of adsorbed species (white) on a rough surface. The ratio of the contour defined by the centers of adsorbed species and the proper surface contour provides information about the available adsorption surface area, and the contribution of excluded areas.

the rough surface approaches the behaviour of a smooth surface (case 3). In the 2D-space (Fig. 13) the excluded volume is represented by the difference between the real surface contour and the contour defined by the centres of adsorbed species.

The three possibilities can be approached for a number of reactions. Examples of case 1 are $H$ electrosorption on rough $\mathrm{Pt}[36], \mathrm{O}$-electrosorption on rough $\mathrm{Pt}$ and $\mathrm{Au}[37]$, CO-adsorption on rough $\mathrm{Pt}[38], \mathrm{CO}_{2}$-electroadsorption on rough $\mathrm{Pt}[39], \mathrm{Cd}$ and $\mathrm{Pb}$-upd on $\mathrm{Ag}$ dendrites [40], and glucoseelectroadsorption on rough $A u[41-43]$. In all these the surface roughness factor determined by the electroadsorption charge becomes independent of the yardstick size (Fig. 13).

An example of case 2 is the adsorption of 1,10 phenanthroline on stabilized rough $\mathrm{Au}$ electrodes with $D_{\mathrm{s}} \cong 2.2[44]$. The voltammograms of the stabilized fractal gold electrodes $(R=52)$ recorded at $0.1 \mathrm{Vs}^{-1}$ in $0.1 \mathrm{M} \mathrm{HClO}_{4}$ show the typical shape of the polycrystalline gold with peaks $A$ and $C$ corresponding to the formation of the gold oxide monolayer and its electroreduction, respectively (Fig. 14a)[37]. After 1,10-phenanthroline electroadsorption at $E=0.1 \mathrm{~V}$ the voltammograms exhibit a number of subtle differences (Fig. 14b). Although adsorption/desorption peaks are not apparent in the double layer region, it is clear that 1,10-phenanthroline has some influence on gold oxidation. However, the magnitude of the oxidation current does not 


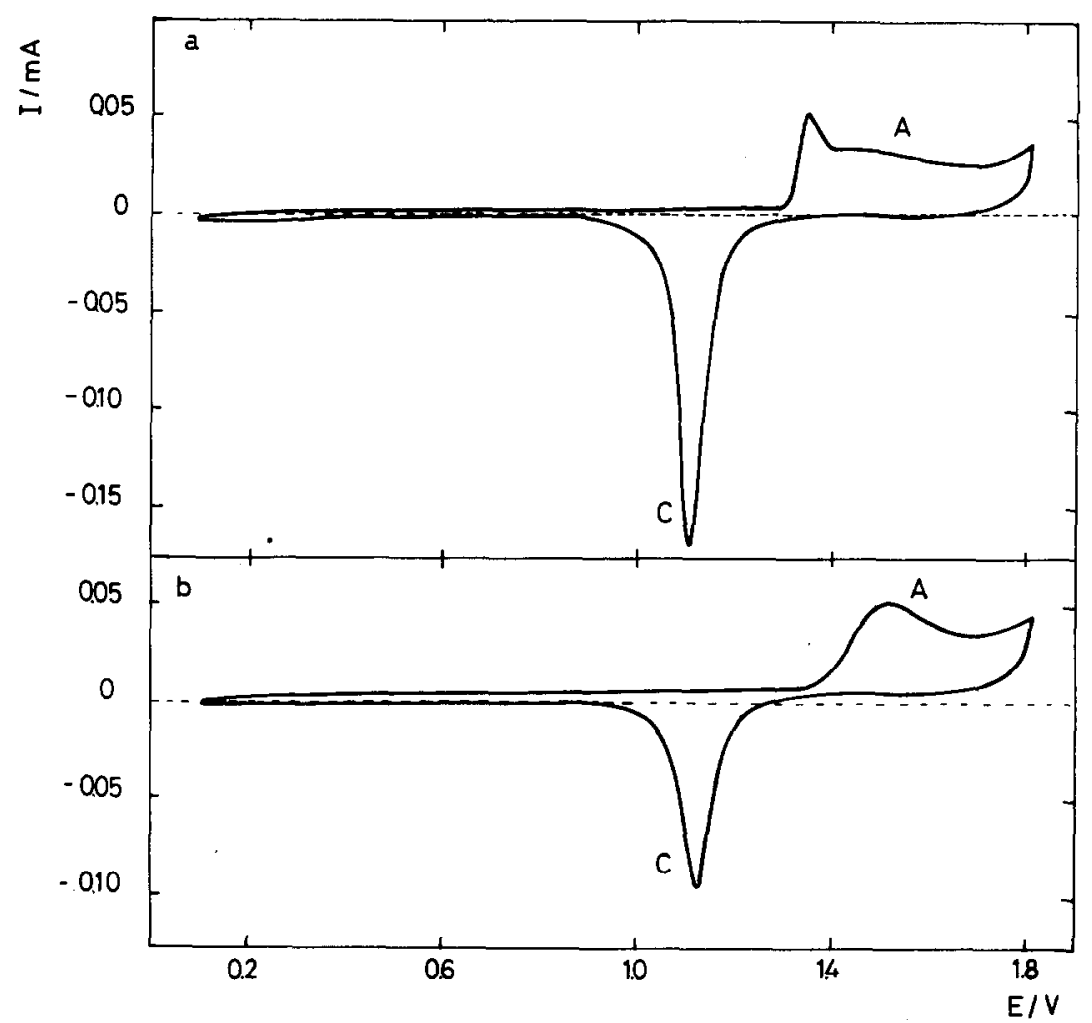

Fig. 14. Voltammograms of $\mathrm{Au}$ electrodes $(R=1)$ run at $0.1 \mathrm{~V} \mathrm{~s}^{-1}$ and $25^{\circ} \mathrm{C}$ in (a) $0.1 \mathrm{M} \mathrm{HClO}_{4}$, and (b) $0.1 \mathrm{M} \mathrm{HClO}_{4}+5 \times 10^{-4} \mathrm{M}(1,10)$-phenanthroline.

appear to be affected to a large extent and remains independent of the 1,10-phenanthroline concentration as observed for related compounds [45]. Hence, it appears that in the $0.8-1.8 \mathrm{~V}$ (vs. nhe) range 1,10 phenanthroline oxidation is precluded. Therefore, the charge decrease in current peak $B$ in the absence and in the presence of 1,10-phenanthroline can be attributed to the partial blocking of the electrode surface by the adsorbed organic molecules.

On the other hand, the specific capacitance $\left(C_{\mathrm{d}}\right)$ vs. potential $(E)$ plots for smooth and rough $\mathrm{Au}$ electrodes obtained in $0.1 \mathrm{M} \mathrm{HClO}_{4}$ and $0.1 \mathrm{M} \mathrm{HClO}_{4}$ $+x M 1,10$-phenanthroline $\left(5 \times 10^{-4} M<x<5 \times\right.$ $10^{-3} \mathrm{M}$ ) differ markedly due to the 1,10 -phenantholine adsorption. Thus, the curves are shifted by a constant value towards lower $C_{d}$. Furthermore, in the $0.2-0.7 \mathrm{~V}$ potential range the minimum in the plots and the hump at $-0.2 \mathrm{~V}$ observed in the supporting electrolyte-containing solution tend to disappear. The increase in the 1,10 -phenanthroline concentration $(c)$ results in the progressive decrease in $C_{d}$.

The degree of surface coverage $(0)$ by 1,10 -phenanthroline can be easily estimated from the reduction in $Q_{\mathfrak{c}}$, the O-electrodesorption voltammetric charge, with respect to the value resulting from supporting electrolyte-containing solutions. For this purpose, $\theta$ is defined by $\theta=1-\left(Q_{c}^{*} / Q_{c}\right)$, where $Q_{c}^{*}$ and $Q_{c}$ are the electroreduction charges after and before 1,10phenanthroline electroadsorption, respectively.

The $\theta$ vs. $c$ plots (adsorption isotherms) for columnar $A$ u clectrodes with $R$ values in the $1 \leqslant R \leqslant 55$ range are displaced towards lower $\theta$ values as $R$ increases (Fig. 15). The adsorption isotherms seems to fulfil a Frumkin-type isotherm:

$$
\beta c=\theta \exp (-2 a \theta) /(1-\theta),
$$

where $a$ is a complex interaction parameter, and $\beta$, the adsorption coefficient, is given by:

$$
\ln \beta=-\Delta G^{\circ} / R T,
$$

$\Delta G^{0}$ is the free energy of adsorption, $T$ is the absolute temperature and $R$ is the universal gas constant.

Accordingly, the $\ln \theta /(1-\theta) c$ vs. $\theta$ plots give straight lines which exhibit increasing slopes as $R$ increases but yield the same $\beta$ value for $\theta=0$. The estimated $\Delta G^{0}$ values for the columnar electrodes with different $R$ values give $\Delta G^{0}=-26 \pm 1.5 \mathrm{~kJ} \mathrm{~mol}^{-1}$, indicating a weak 1,10 phenanthroline/gold interaction. On the other hand, the $a$ values change from $a \cong-10$ to $a \cong-14$, as $R$ increases from 1 to 55 . The negative sign in the parameter $a$ could indicate repulsion between the adsorbed molecules. However, it is difficult to see the physical origin of these phenomena. Conversely, this parameter should reflect the presence of excluded volumes in the rough stabilized $\mathrm{Au}$ surface. The molecular size of 1,10-phenanthroline calculated using the MM2 method is $\cong 10^{-14} \mathrm{~cm}^{2}$, and accordingly, the molecule radius should be $r_{\mathrm{m}} \cong 4$ $\times 10^{-6} \mathrm{~cm}$. Although this value appears to be small when compared to $r_{\mathrm{p}} \cong 3 \times 10^{-7} \mathrm{~cm}$, from STM results, it is possible that the organic molecule probes the small side tail of the pore size distribution as no excluded volume effects were detected using $\mathrm{CO}_{2}[39]$ and glucose[41-43]. Thus, it is reasonable to assume that a number of pores cannot be reached 


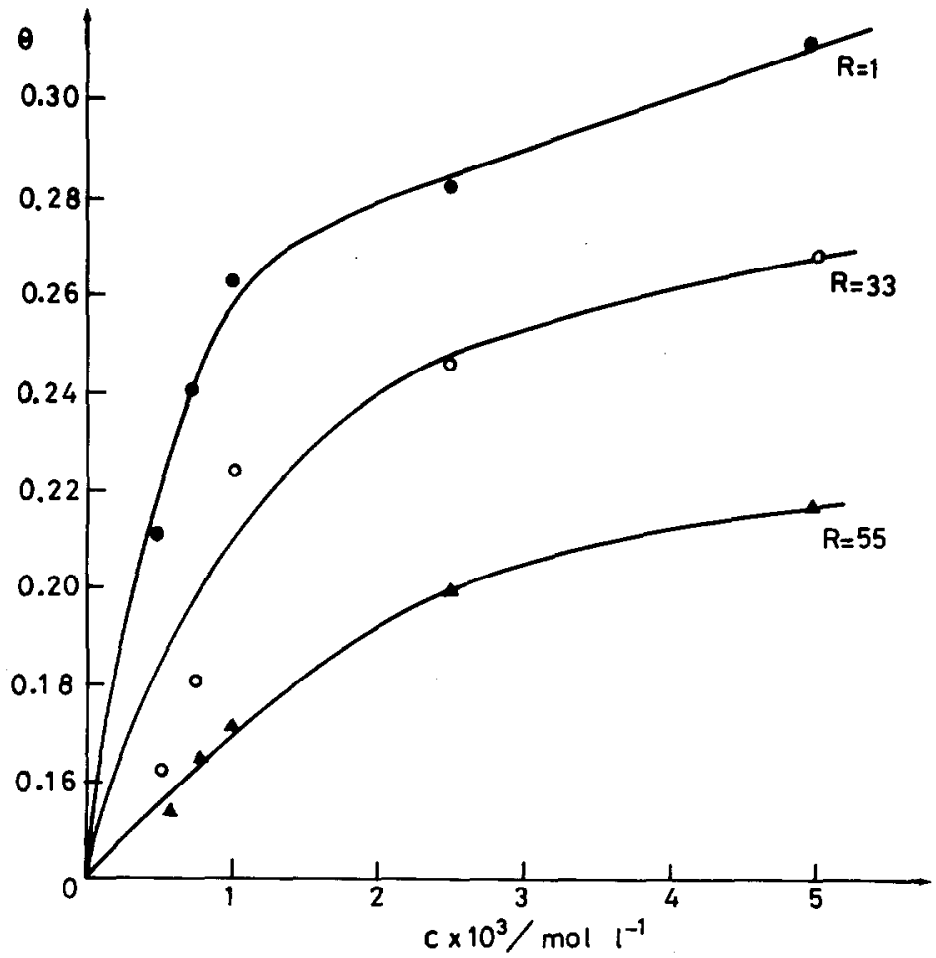

Fig. 15. $\theta$ vs. $c$ plots for $(1,10)$-phenanthroline adsorption in $0.1 \mathrm{MHClO}_{4}$ at $25^{\circ} \mathrm{C}$ on columnar $\mathrm{Au}$ electrodes with different $R$ values at a constant potential, $E=0.75 \mathrm{~V}$ (vs. rhe).

by the organic molecules which leads to a decrease in the available adsorption area. Finally, an example of case 3 can be approached through the adsorption of a molecule with an average size larger than the average pore size of the electrode surface. This is the case of the adsorption of thymol blue [44], a molecule with an average cross-section greater than $10^{-14} \mathrm{~cm}^{2}$ on a stabilized rough Au electrode in an aqueous solution. In this case, the surface coverage referred to the overall surface is markedly decreased as expected from the present model as $A / S \Rightarrow \infty$.

\section{CONCLUSIONS}

New topographic approaches based on the fractal geometry supported by surface imaging at atomic and $\mathrm{nm}$ levels make the gap between ideal and real surfaces either continuous or discontinuous much narrower. The use of fractal geometry allowed us to obtain relevant information about the degree of surface disorder, the surface growth mechanism, and to predict the kinetics of electrochemical reactions at these surfaces. This description of the topography of irregular solid surfaces can explain a large number of frequent kinetic deviations in the behaviour of real systems from simple laws.

A quantitative description of roughness can be accomplished by the application of the dynamic scaling theory to STM images of rough metal surfaces.

The knowledge of the dynamics of rough solid surfaces provides new ways for handling the properties of these surfaces including their stability in different environmental and working conditions.
The possibility of producing electrode materials with pre-established concentration of particular reacting sites, topography and degree of dispersion can be envisaged from the present approach of the irregular surface topography.

Columnar and dendritic electrodeposit surfaces can be taken as models to study irregular solid surfaces with anisotropic and isotropic strong disorder.

Acknowledgements-Authors thank the Consejo Nacional de Investigaciones Científicas y Técnicas (Argentina) for financial support of the research project on the physical chemistry of rough solid surfaces at INIFTA.

\section{REFERENCES}

1. G. Somorjai, Chemistry in Two Dimensions: Surfaces. Cornell University Press, Ithaca (1981).

2. F. Jona and P. Marcus, in The Structure of Surfaces II (Edited by J. F. Van der Veen and M. A. VanHove). Springer Verlag, Berlin (1988).

3. M. P. Soriaga (Editor), Electrochemical Surface Science, Molecular Phenomena at Electrode Surfaces. American Chemical Society, Washington, DC (1988).

4. G. Binnig, H. Rohrer, Ch. Gerber and E. Weibel, Appl. phys. Lett. 40, 178 (1982).

5. R. J. Behm, N. García and H. Rohrer (Editors), Scanning Tunnelling Microscopy and Related Methods. Kluwer (1990).

6. R. Sonnenfeld, J. Schneir and P. K. Hansma, Modern Aspects of Electrochemistry (Edited by R. E. White, J. O'M. Bockris and B. E. Conway). Vol. 21, Chap. 1, p. 1. Plenum Press, New York (1990).

7. P. Pfeifer and M. Obert, in The Fractal Approach to the Heterogeneous Chemistry (Edited by D. Avnir) p. 11. J. Wiley, New York (1989).

8. B. B. Mandelbrot, The Fractal Geometry of Nature. W. H. Freeman, New York (1982). 
9. L. Vázquez, A. Hernández Creus, P. Carro, P. Ocón, P. Herrasti, C. Palacio, J. M. Vara, R. C. Salvarezza and A. J. Arvia, J. phys. Chem. 96, 10454 (1992).

10. D. Farin and D. Avnir, in The Fractal Approach to the Heterogeneous Chemistry (Edited by D. Avnir), p. 271. J. Wiley, New York (1989).

11. M. V. Berry and Z. F. Lewis, Proc. Roy. Soc. London A370, 459 (1980).

12. F. Family, Physica A168, 561 (1990).

13. J. F. Gouyet, M. Rosso and B. Sapoval, in Fractals and Disordered Systems (Edited by A. Bo and S. Havlin), p. 231. Springer-Verlag, Berlin (1991).

14. A. Bunde and S. Havlin (Editors), Fractals and Disordered Systems. Springer Verlag, Berlin (1991)

15. R. C. Salvarezza, L. Vázquez, P. Ocón, P. Herrasti, J. M. Vara and A. J. Arvia, Europhys. Lett. 20, 727 (1992).

16. L. Vázquez, R. C. Salvarezza, P. Ocón, P. Herrasti, J. M. Vara and A. J. Arvia, Phys. Rev. E, in press.

17. J. M. Gómez-Rodriguez, L. Vázquez, A. Baró, R. C. Salvarezza, J. M. Vara and A. J. Arvia, J. phys. Chem. 96, 347 (1992).

18. J. M. Gómez-Rodríguez, A. Asenjo, R. C. Salvarezza and A. M. Baró, Ultramicroscopy 42-44, 1321 (1992).

19. C. Alonso, R. C. Salvarezza, J. M. Vara, A. J. Arvia, L. Vázquez, A. Bartolomé and A. M. Baró, J. electrochem. Soc. 137, 2161 (1990).

20. P. García, M. M. Gómez, R. C. Salvarezza and A. J. Arvia, J. electroanal. Chem. 347, 237 (1993).

21. B. K. Chakraverty, J. Phys. Chem. Solids 28, 2401 (1967).

22. S. Real, R. Vilche and A. J. Arvia, J. electroanal. Chem. 341, 181 (1992).

23. C. Alonso, R. C. Salvarezza, J. M. Vara and A. J. Arvia, Electrochim. Acta 35, 1331 (1990).

24. N. A. Gjostein, in Surfaces and Interfaces I (Edited by J. Burke, N. Reed and W. Reiss). Syracuse University Press, New York (1967).

25. T. Pajkossy and L. Nyikos, Electrochim. Acta 34, 171 (1989).
26. P. Ocón, P. Herrasti, L. Vázquez, R. C. Salvarezza, J. M. Vara and A. J. Arvia, J. electroanal. Chem. 319, 101 (1991).

27. W. Scheider, J. phys. Chem. 79, 127 (1975).

28. R. de Levie, Electrochim. Acta 10, 113 (1965).

29. M. M. Gómez, L. Vázquez, R. C. Salvarezza, J. M. Vara and A. J. Arvia, J. electroanal. Chem. 317, 125 (1991).

30. A. Le Méhaute and G. Crépy, Solid State Ionics 9-10, 17 (1983).

31. L. Nyikos and T. Pajkossy, Electrochim. Acta 30, 1533 (1985).

32. P. Meakin and B. Sapoval, Phys. Rev. A43, 2993 (1991).

33. A. Hernández Creus, A. E. Bolzán, P. Carro, S. González, R. C. Salvarezza and A. J. Arvia, Electrochim. Acta, 38, 1545 (1993).

34. S. H. Liu, Phys. Rev. Lett. 55, 529 (1985)

35. T. Pajkossy, J. electroanal. Chem. 300, 1 (1991).

36. A. C. Chialvo, W. E. Triaca and A. J. Arvia, J. electronal. Chem. 146, 43 (1983).

37. A. C. Chialvo, W. E. Triaca and A. J. Arvia, J. electroanal. Chem. 171, 303 (1984).

38. A. M. Castro Luna, M. C. Giordano and A. J. Arvia, J. electroanal. Chem. 259, 173 (1989).

39. M. L. Marcos, J. M. Vara, J. González Velasco and A. J. Arvia, J. Electroanal. Chem. 224, 189 (1987)

40. A. Hernández Creus, P. Carro, S. González, R. C. Salvarezza, and A. J. Arvia, J. electrochem. Soc. 139, 1064 (1992).

41. A. M. Castro Luna, A. E. Bolzán, M. F. L. de Mele and A. L. Arvia, Z. Physikal. Chemie (NF) 160, 25 (1988).

42. A. M. Castro Luna, A. E. Bolzán, M. F. L. de Mele and A. J. Arvia, Pure appl. Chem. 63, 1599 (1991).

43. A. M. Castro Luna, A. E. Bolzán, M. F. L. de Mele and A. J. Arvia, J. electroanal. Chem. 323, 149 (1992).

44. P. García, M. M. Gómez, R. C. Salvarezza and A. J. Arvia, submitted.

45. L. Stolberg, J. Richer, J. Lipkowski and D. E. Irish, J. electroanal. Chem. 207, 213 (1986). 